\title{
Omnichannel for Learning
}

DOI: https://doi.org/10.17230/9789587207002lch2

\author{
Marta S. Tabares
}

Paola Vallejo

\section{Introduction}

From an early age, the "digital natives" generation has naturally adapted to electronic devices in their homes, schools, and workplaces by interacting with different environments through computer technologies. Prensky (2001) said that digital natives have adopted parallel habits associated with the development of multiple tasks. For instance, they prefer to receive information graphically and find satisfaction with immediate feedback about their progress.

These characteristics identify individuals who are more likely to access virtual education programs or complementary education courses to increase their professional level. Although virtual learning environments are not a new academic space, computer technologies for virtual or digital education are currently undergoing accelerated use and consequently require innovative development. The massive worldwide incursion of virtual courses, academic platforms, and higher education programs have significantly impacted countries in constant growth, such as Colombia. Today's view of digital transformation is influenced by the accelerated evolution of mobile devices and their technological elements that move world trade and generates a cultural change. This change directly impacts the educational process by generating challenges and establishing new teaching and learning styles.

Recent technological developments in data management and processing, linked to the advancement of countless new digital channels, offer the possibility of managing information and distributing it to different types of users globally. In other words, users can access different services through different channels. The services they access meet the needs, requirements, and particularities to guide the microsegmentation and personalization of supply and demand. Notably, 
personalization is possible due to information technologies that have had their best expression in marketing. Micro-segmentation is individualized to understand and recognize behavior patterns, preferences, purchasing power, needs, aspirations, and other variables to offer users tailormade products and services. Many information technologies, data, and capacities are joined together to sell better, in greater quantity, and with greater efficiency and impact. Which brings forth the question: Why not use the same marketing strategies to educate better with more coverage and greater efficiency and impact?

This chapter presents the research results demonstrating that it is possible to improve the efficiency and impact on education using distribution and communication strategies (in this case, educational services and content) similar to those used in marketing. The research objective was achieved by a series of technological components and analytic models articulated through a technological platform. A set of digital channels, such as the web and email, facilitated the capture of learning experiences merged with variables related to ubiquitous contexts.

A learning engine maximized the learning process by using the most appropriate channel for each learner profile. By enabling these channels, different variables of the context derived from the data characterized the user's actions. Conventional variables included: location, movement, noise, learning rhythm, individual learning style, preferences in using the content, responses to evaluations, and other elements of virtual learning spaces. Learners could link different virtual elements of their learning (e.g., microlearning) with or without an intelligent engine to personalize or adapt experientially; thereby, motivating satisfactory attitudes, retention, achievement, and overall quality and learning efficiency.

The research experience allowed us to identify and instigate technological challenges with mobile learning and ubiquitous learning. Big Data, advanced analytics, and Artificial Intelligence provided students with an omnichannel learning engine that enabled learning anywhere, any time, and with any device. These characteristics provided experiential learning seven days a week and for 24 hours a day in context, and integrated features, constraints, and conditions related to its use at a given time. These factors ensured improvements in the quality, satisfaction, retention of students, effectiveness, and impact on the virtual learning processes in the Department of Antioquia. 
The chapter answers the research Question

What model should integrate elements in intelligently

mobile and ubiquitous learning as an articulation of channels,

information sources, content for learning, and variables of a

digital context-aware following an omnichannel strategy that

places the student at the center of the process and responds to

their particularities, challenges, and learning place?

The methodology adopted for the project's development was proposed by Hevner et al. (2004). It offered an appropriate paradigm for the study of phenomena of behavioral science and design science. The development of the different activities was accompanied by other methodologies or models of development and innovation including Design Thinking (Lewrick \& Link, 2018), Scrum (Schwaber, 2004), Lean Startup (Croll \& Yoskovitz, 2013; Ries, 2011), and ASUM-DM (adapted by Angée et al., 2018). The use of these methodologies aimed to achieve a TRL 6-7 product (Hicks et al., 2009).

\section{Background}

According to the Colombian National Administrative Department of Statistics (DANE in Spanish), in 2019 the largest population in Colombia were individuals between 14 and 18 years old amounted to $26.1 \%$; and residents between 18 and 26 years represented $16 \%$ of the population. These findings suggest that $42.1 \%$ of the Colombian population corresponds to people who are part of the "digital natives" generation. Developed characteristics include the "preference for speed, nonlinear processing, multitasking, and social learning, allegedly developed through immersion in digital technology during childhood and adolescence when neural plasticity is high" (Prensky, 2001). Digital natives are hyperconnected by going from one channel to another using different devices and technologies.

The intrinsic characteristics of the target population for distance education programs have not been decisively integrated into the curriculum or its teaching methods. This affirmation is even more relevant when related to virtual programs. Due to their digital nature, virtual programs should be evaluated to consider characteristics highly aligned with the digital natives by integrating multiple channels, resources, 
and contents. To satisfy the needs of digital natives, it is pertinent to consider the traditional means of virtual education (e.g., MOOC, web, and LMS) and include the additional channels, resources, and interaction mechanisms between students. Furthermore, it must be decided whether the enriched element of virtual education improves learning processes, student retention, and overall satisfaction for digital natives and students of virtual programs (Zmuda et al., 2015).

In Colombia, the Informe Nacional de Competitividad (2017) revealed that the evolution of higher education coverage has accelerated in recent years. The rates went from $37 \%$ in 2010 to $51.5 \%$ in 2016. While this is above average for Latin America, $51.5 \%$ was far below the $76 \%$ that corresponds to the OCDE rate. In 2016, the National System for Higher Education Information reported that the coverage in Antioquia was $55 \%$, which was higher than the national average. The Ministry of National Education informed that the country had a dropout rate of nearly half of the tertiary education students. This was due to the advances in coverage, the retention of students, and considering them fundamental for the competitiveness strategy and the Plan de DesarrolloAntioquia Piensa en Grande (2016). We are currently working on solutions to deeply integrate Information and Communication Technologies (ICT) in education because this opens up the possibility of improving the education quality, recognizing students' current contexts, and providing access for more people. In 2016, the UNESCO-UNIR Congress (2016) supported this objective with the following statement: "Education is less and less physical, that is to say, more virtual, through pedagogical strategies it should be possible to overcome the challenges of coverage, access, equity, quality, among others, from the use of ICT technologies".

In general, Colombia and Latin America have introduced distance training programs, with the recent addition of virtual programs, to reach different regions. The Department of Antioquia has experienced an evolution of different training methodologies for higher education. In the 2015-2016 period, there was an accelerated growth of virtual training, coinciding with the increase in coverage of Internet networks after the 2010 launch of the project called Vive Digital of the Ministry of Information Technology and Communications (MinTIC). This project offered significant progress in the massification of Internet use and higher availability of smartphones. According to the MinTIC, the 
high growth included the number of Colombians who have equipment that allows them to connect to broadband Internet is growing. While in 2015, for every 100 Colombians there were 54.5 terminals, in 2016, the figure rose to 69.55 . The advances of virtuality go hand-in-hand with the massification of ICTs and its complete appropriation in education to prompt development. According to the country's digitalization index, the country has reached the advanced stage of its digital ecosystem. This development of infrastructure and access to ICT is viable and imperative to close the gaps in higher education.

Today, the impacts of digital society, technology, and tools for consumers are advancing. An example of these advances is the omnichannel concept. In the past, if a consumer wanted to buy a product, they would go to a local store, view the different options, and make a purchase. As the world evolved, the purchase decision became a little more complicated. The consumer started to get information through other channels such as specialized magazines that offered various products. Then came the Internet which introduced new possibilities for surfing, researching, and buying online.

The evolution continued with the addition of laptops, tablets, and smartphones that give consumers multiple options to meet their purchasing needs. They can choose to shop in the physical store or through a desktop computer, laptop, smartphone, or smart TV. Consumers can interact with social media and discover new products via email, messaging, posting, or by visiting websites with their smartphone, talk to friends about their experiences with a product, or perform other services through different digital channels. Companies that focus on maximizing each channel's performance, store, phone, web, mobile, etc., have a multichannel strategy. An omnichannel approach puts the customer at the center of their strategy. This approach recognizes that customers can be approached or attracted to companies or brands in many ways. The main goal is to create a better customer experience making it appear as if the brand were communicating and working with each costumer. This is possible by providing the user with a more consistent experience. The main characteristics of an omnichannel strategy are:

- The user is the center: This principle is key when creating omnichannel experiences to ensure that a user can finish a process through different means and devices and with no interruptions. 
This defines the type of user, their needs, and whether they had a memorable experience when using a channel's services.

- Consistency: It is essential to define the parameters that will help users complete tasks virtually. It must be defined how to take the functionalities to the different points of contact so the user does not have to undertake a new learning process for each of them.

- Neutral information: Starting from the premise of neutral information in an omnichannel project, it will allow similar decisions for certain functionalities that are vital for the users. In this way, clients can go from one point of contact to another without interruptions or delays.

- Context: The all-channel experience must consider the user context. This involves asking questions such as: What data plan will my user have? What device will he/she use? Is he/she a digital native? Will he/she have the level of technology adoption that we need?. The answers to these questions will help define an appropriate road map to make the right decisions for users.

- Availability: This characteristic implies that the correct decisions are being made about the user. It is important to determine the impact that each decision has on end-users. It is also important to define the scope of options that users will have when using select tools to avoid frustrating them in certain moments when they expect functionality and response.

- Strategy: An action plan provides a way to achieve omnichannel experiences that remain in the memory of users. Attention to detail is indispensable. It is necessary to define how to impact people's lives and what added value is available to users. Beyond a clean interface or an innovative design, it has to consider the user's current experience and what will encourage them to return in the future.

Digital natives already use channels such as email and the more popular social networks such as Twitter and Facebook. Students are digital consumers who enjoy more interactive and personalized experiences thanks to mobile and ubiquitous technologies. This leads us to ask if it is possible to use omnichannel marketing strategies to educate better and with greater efficiency and impact?

The benefits of omnichannel and current students' characteristics were the motivating factors for researching and developing a proposal for 
education. The aim was to provide memorable experiences, centralize information, and integrate different communication channels to offer students information and educational content to solve doubts. The student must be the center of the entire training strategy, both in face-to-face and online education. This facilitated the organization of their learning and the necessary access to the contents of interest. The references for this project's development consisted of 277 virtual education programs offered by 35 Colombian universities. None of the 277 programs had advanced analytic engines, Big Data, or Artificial Intelligence that leveraged mobile learning in a dynamic, personalized, intelligent, and real-time way; allowed the articulation of multiple channels and sources; or dynamically depended on the profile of the students. The channels used in the 277 referenced programs were mostly traditional and unidirectional. None captured the context of the student, even though channels such as intelligent chatbots, bidirectional SMS, telepresence, web services, context geodata, articulation with data of the study environment, among others, could have been used to enrich the experience during the learning process. There were no developments that allowed the articulation of multiple channels in an omnichannel strategy. It placed the student at the center of the learning process and articulated the set of channels, the course content, and other resources according to the student, their needs, requirements, their geodata, and learning style so that mobile learning and experiential and adaptive learning was enabled.

This project focused on developing a virtual education tool that contextualized training processes, customized content, and prompted microlearning from a system that integrated ICT technologies in the educational process. It allowed access to virtual content through different channels and a more significant interaction and collaboration between all educational community members including the institution, teacher, learner, and the environment. This research's novelty revealed the reality of multiple simultaneous training channels under mobile user platforms such as those used today by the industry in virtual training processes. The project complements the tools currently used by the existing virtual education in the Department of Antioquia. It precedes an auspicious moment for both the region and the country by allowing new virtual instruments to reach all regions, in all academic segments. Moreover, it expands its scope to acknowledge disciplines that require contact with 
physical realities with training programs, which are the fundamental axis of all government plans to create equity and competitiveness.

The research is associated with the challenges established in the 804 Minciencias' call (Colombian Ministry of Science, Technology and Innovation). This project is in the category of Mobile learning in virtual education.

\section{Research Methodology}

The proposal is developed by following the Design Science in Information Systems Research (ISR) methodology. Innovation and agile methodologies like Design Thinking, Lean Startup, Scrum, and ASUM-DM support its development. Every methodology provides phases, activities, or elements to perform research and achieve a technology product near the TRL 6-7 innovation context. They interact in a highly iterative loop and each phase provides discoveries that may require revisiting previous steps. Figure 1 illustrates the process.

Figure 1: Design Science in IS Research merged with Design Thinking, Lean Startup, Scrum, and ASUM-DM.

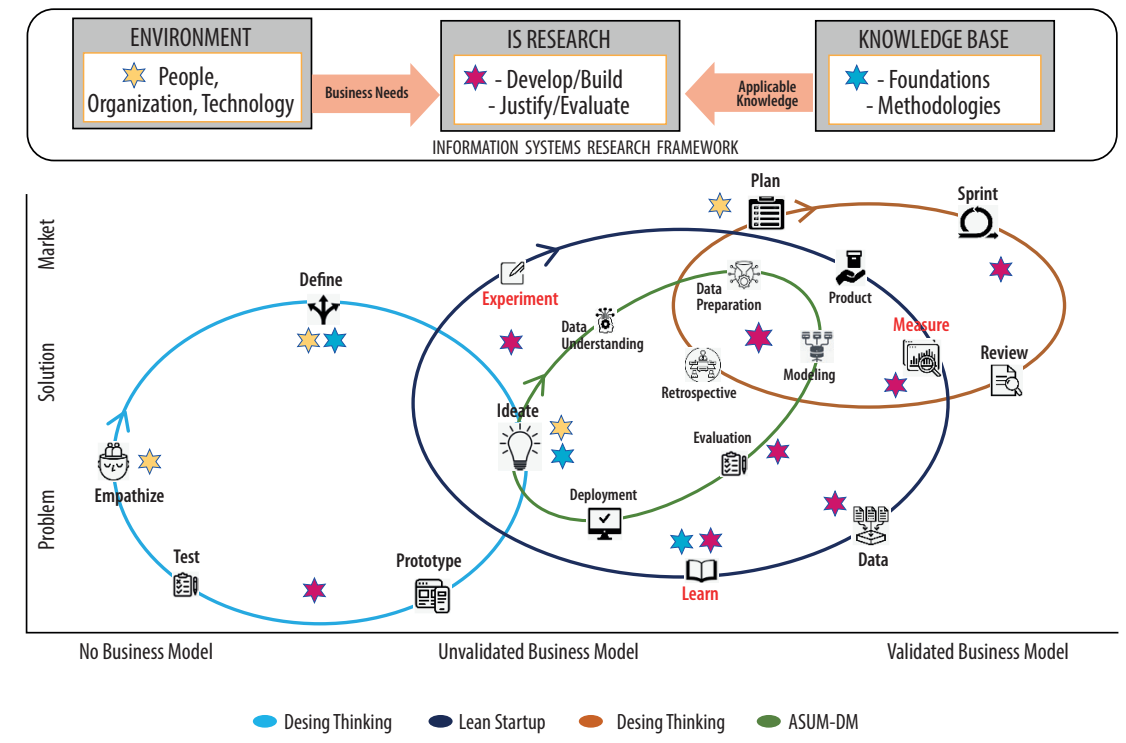

Source: Prepared by the authors 
The following describes the main elements of the Design Science ISR methodology and its use through different phases.

\section{Environment}

The environment defines the problem space which is composed of people, organizations, and technology. Two groups, the Target Group and the Project Team, are considered. The Target Group consisted of individuals of the learner role. They were identified from the business' needs and classified through the working progress. The Project Team was responsible for creating and evaluating information technology artifacts to solve different government's virtual education viewpoints. The whole team worked with the Target Group to empathize with them and put themselves in the user's position and observe them in detail. The Project Team consisted of four subgroups:

- Creatives: Individuals responsible for understanding the client's educational needs and define the project's basis. They recognize the environment, and establish what the problem is. The group made up of higher education researchers and startups provided ideas that resulted from a research project to achieve an innovative solution. They created the following Researchers, Engineers, and Data Scientists subgroups to be part of the strategic plan and execute the defined activities and achieve the main objective.

- Researchers: Individuals with research capabilities to create new knowledge and scientific outcomes. Senior researchers and postgraduate and undergraduate students are part of this group. They had the responsibility to carry out reviews (e.g., a Systematic Mapping Review) and identify the concepts to be applied and developed in the project. This subgroup is part of the proposed development joined with the Data Scientist subgroup.

- Engineers: Individuals with skills in the design and development of information technology products. They must perform tasks of primary research when new technologies are required to create complex architectures. They must have experience by working with agile methodologies.

- Data Scientists: Individuals with skills in data mining, machine learning, deep learning, and visualization. They worked with data analytics and methodologies as CRISP-DM or ASUM-DM. 
The Creatives group executed the phases provided by Design Thinking and Lean Startup methodologies. They began with the Empathize phase to understand the users, their needs, and expectations. Then Creatives and Researchers defined the problem statement that guided the Project Team throughout the design process and the challenges that needed to be addressed. At the Ideate phase, the whole Project Team intervened to propose possible solutions that subsequently turn into prototypes that real users would test. The Prototype phase focused on turning ideas into something tangible, thus allowing the Project Team to gather feedback before developing the whole product. During the Test phase, the Target Group interacted with the prototype by highlighting any design flaws that the Engineer subgroup would quickly fix.

Likewise, the Lean Startup methodology allowed the application of a scientific approach by providing activities to validate each hypothesis proposed by the Researchers and Data Scientists subgroups before further building. This reduced the risk provided by an unknown and uncertain environment. It was the fundamental principle that each hypothesis must be tested and confirmed by experimentation before proceeding to the next phase. We were always sure to build on solid foundations with validated knowledge. The Lean Startup focused on a three-phase circuit that was completed in the shortest possible time and with minimum investment. The Build phase created a product tailored to the customer needs. When data was not enough to create a product wholly adjusted to the Target Group's needs, the idea was to create a minimum viable product. This product must be a version with the minimum functionalities that collected the maximum amount of learning validated about the Target Group. In the Measure phase, the biggest challenge was to measure how the Target Group responded, and, from this data, make appropriate decisions. The Learn phase revealed if the business was viable and would continue to persevere, or if the pivotal ideas were not working properly and needed to be adjusted. In our proposal, the Ideate phase of the Design Thinking methodology provided activities to generate ideas.

In the Plan phase of the Scrum process, a negotiation between the product owner and the team members was performed. During the meeting, the next tasks were prioritizing through a sprint backlog. Each time an idea was accepted, a Sprint was activated by the Engineers subgroup to achieve a small product in a development cycle complemented by other 
members of the Project Teams. This released the working version of a product more frequently. Once a sprint finished, in the Review activity, the Project Team demonstrated their work results. This allowed for frequent measurement of the project's progress. Then, the Retrospective activity discussed the project process, analyzed what was right, what could be improved, and how to make the teamwork more efficient.

Lastly, ASUM-DM facilitated the implementation of big data and analytic processes. Specifically, this methodology supported data objectives and requirements. The Data understanding allowed initial data collection, as well as identifying data quality issues. Then, in the Data preparation activity, data cleaning was performed. This covered all activities to construct the final dataset from the initial raw data. The Modeling activity allowed us to build models using data mining tools. The Evaluation activity determined if the results met the project objectives and identified the issues that required an early arrangement. Finally, the Deployment activity allowed us to put the resulting models into practice. In this proposal, the Data Scientists subgroup played a significant role by following this methodology's activities.

\section{Knowledge Base}

The base of knowledge was to drive through the experiences and expertise of the Project team, mainly from the Creatives and Researchers. Referencing the knowledge base was essential to guarantee that the results are research contributions and the product of the application of appropriated theories and methods. First, a Systematic Mapping Review (SMR) was developed. The objective of the SMR was to trace and categorize the existing literature on mobile learning, ubiquitous learning, and omnichannel for education. This SMR included a systematic search for articles published in high-level journals or events, mainly from 2010. It should report on quantitative or qualitative researches that demonstrated experimentation on topics related to ubiquitous and mobile learning, omnichannel (from retail), context-awareness, and analytical models applied to them. A detailed synthesis of the articles within the different categories identified the potential value and how the search findings would be maximized (O'Cathain et al., 2014). In this stage, the 
methodologies to be adopted to realize the project were also selected and studied. Subsequently, an analysis of the existing models and tools was carried out.

\section{IS Research}

To initiate the proposal, the Project Team devised activities and tasks to develop the ideas defined by the Target Group. The primary outcomes were achieved by using an agile plan that was defined and accomplished to organize the work of the Project Team and Target Group. By taking advantage of functionality as it was implemented and following the expectations of how funding execution must be done, results were then compared to the expected profit. The two main activities carried out at this stage were:

- Develop/Build: End-user motivations and business needs were considered to identify ideas generated by brainstorming. The gathered ideas were transformed into different artifacts such as user apps, channel managers, and an intelligent engine to guide the focus group's learning process. The activity drove the beginning of a business model that could potentially unlock the expected products (TRL 6-7). Here, the agile plan defined sprints including prototyping, experimentation, data understanding and preparation, modeling, measuring (through evaluation/testing sub-tasks), and development.

- Justify/Evaluate: At the end of each sprint, the Project Team reviewed the achieved product to learn from the focus group and determined how it could be improved. Several sprints could be required because the product is defined from the research process.

\section{Literature Review}

Different scientific domains have contributed to addressing mobile learning and ubiquitous learning, as well as their challenges throughout the years. Table 1 presents our lines of review with the definition of the main concepts. 
Table 1: Literature Review Lines

\begin{tabular}{|l|l|l|}
\hline Learning & $\begin{array}{l}\text { Electronic } \\
\text { learning } \\
\text { (e-learning) }\end{array}$ & $\begin{array}{l}\text { "Learning supported by digital electronic tools and } \\
\text { media" (Pinkwart et al., 2003). }\end{array}$ \\
\cline { 2 - 3 } & $\begin{array}{l}\text { Mobile learning } \\
\text { (m-learning) }\end{array}$ & $\begin{array}{l}\text { "e-learning that uses mobile devices" (Pinkwart et al., } \\
\text { 2003). }\end{array}$ \\
\cline { 2 - 4 } & $\begin{array}{l}\text { Ubiquitous } \\
\text { learning } \\
\text { (u-learning) }\end{array}$ & $\begin{array}{l}\text { "Learning anywhere and at any time" (Hwang et al., } \\
\text { 2008). }\end{array}$ \\
\hline Context & $\begin{array}{l}\text { Context-aware } \\
\text { "Systems that adapt according to the location of } \\
\text { the user, the collection of nearby people, hosts, and } \\
\text { accessible devices, as well as changes to such things } \\
\text { over time" (Salber et al. 1999). }\end{array}$ \\
\cline { 2 - 3 } & $\begin{array}{l}\text { Context- } \\
\text { awareness }\end{array}$ & $\begin{array}{l}\text { Involves adapting systems to the users or their } \\
\text { environment by capturing and understanding contexts. }\end{array}$ \\
\hline Channel & Multichannel & $\begin{array}{l}\text { "Considers the client as the focus of distribution acting } \\
\text { and aims at making products available at the greatest } \\
\text { number of distribution channels, generating integrated } \\
\text { information and, above all, consistent experiences of } \\
\text { purchases" (Carvalho \& Campomar, 2014). }\end{array}$ \\
\cline { 2 - 3 } & $\begin{array}{l}\text { Omnichannel } \\
\text { adapt to the consumer who demands fast answers and } \\
\text { more options from retail" (Carvalho \& Campomar, } \\
\text { 2014). }\end{array}$ \\
\hline
\end{tabular}

Source: Prepared by the authors

\section{Mobile Learning and Ubiquitous Learning}

Pinkwart et al. (2003) defined electronic learning (e-learning) as learning supported by digital electronic tools and media. According to GuriRosenblit (2005) and González Videgaray (2007), this concept refers to the use of electronic media for different learning purposes, ranging from the classroom's complementary activities to the complete replacement of physical presence. This facilitated online meetings based on pedagogical interactions between students, content, and tutors; therefore, allowing students to interact anywhere using an electronic device.

Pinkwart et al. (2003) and Quinn (2000), defined mobile learning as "e-learning that uses mobile devices". This concept contributed to the development of educational activities through interactions that employ 
mobile phones and tablets, as well as wireless services. Kukulska-Hulme (2005) and Wu et al. (2012) suggested that mobile learning began as a complement to traditional education when students were no longer able to attend classes in predetermined fixed locations.

According to Hwang et al. (2008), ubiquitous learning is "learning anywhere and at any time" (p. 82). This concept is based on ubiquitous technology facilitating the construction of an omnipresent learning environment allowing anyone to learn anywhere and at any time. To Zhao et al. (2010), a learning environment in ubiquitous learning is defined as any scenario which students can be fully immersed in the learning process.

Al-Emran et al. (2018) presented a review of 87 research articles from 2006 to 2018 about the Technology Acceptance Model (TAM) concerning mobile learning. The research in this area is motivated by the cost involved in technology implementation. Educational institutions must understand the factors that affect the students' acceptance of a particular system before investing a lot of funds for developing or purchasing it. Among the findings of this review, most studies focused on the extent of TAM with external variables, followed by factors from other theories and models, usage measures, and contextual factors. It was also found that the TAM model was extended with factors from other theories and models. The main issue frequently addressed among all the studies reviewed was to examine the acceptance of mobile learning by students. Most of the studies analyzed were conducted in Taiwan, Spain, China, and Malaysia and in the fields of the humanities and educational context, followed by the information technology and computer context of higher education.

Cárdenas-Robledo and Peña-Ayala (2018) conducted a systematic review of ubiquitous learning to research the positive effects on learning outcomes of using mobile learning tools in education. The review proposed TULA's nine categories (physical settings, learning sceneries, functionality, domain knowledge, learning paradigms, effects, academic level, devices, and technology) and the taxonomy for ubiquitous learning approaches. The review analyzed 176 approaches built between 2010 and 2017 and classified them according to the TULA perspective. The authors highlight that the main weaknesses in the area are related to the conception of a model of functionalities to be performed by ubiquitous learning approaches, the design of architectures and frameworks to design approaches, the proposal of software engineering to lead the development of approaches, and standardizing and automatizing the development of systems. 
Wang et al. (2017) presented the results of a study on ubiquitous language learning in socio-cultural contexts following three issues: system usefulness, activity usefulness, and activity playfulness in museum learning. The authors examined 12 works achieved between 2009 and 2014 related to mobile technology-supported language learning in museums. An important aspect discussed in the study is how locationbased mobile applications transformed users from passive receivers to active learners. Many of the museums adopted ubiquitous location-based systems using mobile devices to strengthen social ties when students collaboratively worked to perform language learning activities.

Lucke and Rensing (2014) performed an extensive survey on mobile learning and categorized the analyzed works concerning educational settings and the main pervasive technologies used. The authors mentioned software and hardware in their list of areas for future research in mobile learning, concluding that pervasive education will result in a fusion with traditionally isolated education on-site settings could be enriched with information technology, and face-to-face activities could be improved with virtual settings. The authors encouraged researchers to innovate in e-learning through pervasive education, context-awareness, adaptivity, and immersive experiences.

Verbert et al. (2012) presented a survey of context-aware recommender systems that have been deployed in Technology Enhanced Learning (TEL) settings. The survey outlined areas where further work is needed. The authors identified relevant context dimensions for TEL applications, then analyzed existing TEL recommender systems along these dimensions. Finally, they highlighted topics where further research was needed to include context data acquisition, contextual data representation, evaluation studies that assess the impact of individual context elements on the recommendation process, data set shares, privacy, among others.

Martin et al. (2011) investigated the frameworks and middleware systems for facilitating and simplifying mobile and ubiquitous learning applications development. The analysis focused on operating systems, programming languages, and the primary purposes of the studied systems. The authors concluded that further development is needed in frameworks and middleware systems devoted to facilitating the creation of mobile and ubiquitous learning applications to consider different sensors, learning 
objects, services, standards, and platforms for mobile and ubiquitous learning. There is a lack of advanced frameworks that encapsulate the complexity involved in dealing with different sensors. Other fields to be explored are the privacy and security to build systems that guarantee the user's rights.

\section{Context-awareness}

The term context-aware is defined by Salber et al. (1999) to describe "systems [that] adapt according to the location of the user, the collection of nearby people, hosts, and accessible devices, as well as [...] changes to such things over time". Context-awareness tends to involve adapting systems to the users or their environment by capturing and understanding contexts. According to Byun and Cheverst (2004), a learning system is context-aware if it can be extracted and interpreted and its contextual information can be used to adapt its behavior and functionalities to the current context. According to Siadaty et al. (2008), in mobile and ubiquitous environments, the context is summarized in the spatial and temporal aspects of the user's situation. Hwang et al. (2008) give a special definition of ubiquitous learning through the concept contextaware u-learning, which is the employment of "mobile devices, wireless communications and sensor technologies in learning activities" (p. 83). Context-aware analysis in teaching-learning processes has evolved significantly in several emerging fields such as Context-Aware Mobile Learning Applications (CAMLA). The systematic literature review presented by Kumar and Sharma (2019) describes the key components of CAMLA through the extraction and representation of context information, context adaptation, and different types of applications developed. The review identifies different context types of which the student, location, and time are the most frequently used types in CAMLA development.

Hasanov et al. (2019) presented a literature search on Adaptive Context-Aware Learning Environments using a meta-analysis of 53 studies published between 2010 and 2018 identifying variables such as mobile devices, Radio-Frequency Identification, Near-Field Communication, ontology for context modeling approach, context data from the student's profile or location, rule-based adaptation, and informational feedback. The authors proposed a taxonomy of context-aware categories allowing 
them to propose recommendations for future context-aware research on the adaptation of educational applications.

The work presented by Muñoz and González (2019) evaluated and discussed common components in context, feedback techniques, and modeling. They concluded that the most relevant context entities are time, location, device, environment, and the student. The components in common include content delivery, student profiles, context acquisition, question banks, adaptive evaluation, reasoning modules, and feedback modules.

The paper presented by Nye (2015) proposed a literature review on trends and approaches in educational technology. The review focused on the barriers to adopting intelligent tutoring systems and could be applied to any type of educational technology analysis. These barriers included students' basic computer skills, hardware sharing, mobile device restrictions, data costs, electrical reliability, internet infrastructure, language, and culture. The differences and similarities between externally and locally developed tutoring systems were considered. The review concludes with possible future directions and opportunities for research on tutoring systems and other educational technologies on the global stage.

The review by Verbert et al. (2012) assessed the degree of analysis of variables in recommendation systems research for TEL processes. They presented a context framework that identified relevant context dimensions for TEL applications. Based on the results of the review, they describe some issues for which additional research is needed.

Moreover, the systematic review presented by Alsswey and AlSamarraie (2019) identified influential factors and challenges affecting the adoption of mobile learning among the students at universities in Arab Gulf Countries (AGCs). The authors explored the current evidence on the use of mobile learning in AGCs. The results show different factors (i.e., cultural, and social) that contributed to the acceptance/adoption of learning in AGC universities.

The systematic review of Khanal et al. (2019) explored the mobile learning's adoption learning using a selection and analysis methodology for extracted publications, focusing on the publication trend, the adoption models used, and a set of factors influencing the adoption of mobile learning. 


\section{Multichannel vs. Omnichannel}

According to Carvalho \& Campomar (2014), in marketing "the multichannel has a premise to consider the client as the focus of distribution acting and aims at making products available at the greatest number possible of distribution channels, generating integrated information and, above all, consistent experiences of purchases" (p. 103). Furthermore, to Kotler and Keller (2012), each channel has a specific target segment and companies must be careful to ensure that customers can interact through their preferred channels. Additionally, Juaneda-Ayensa et al. (2016) defined omnichannel strategy as

a form of retailing that, by enabling real interaction, allows customers to shop across channels anywhere and at any time, thereby providing them with a unique, complete, and seamless shopping experience that breaks down the barriers between channels (p. 1).

Omnichannel retailing is a phenomenon produced by the emergence of channels and new technologies that allow retailers to integrate all the information these channels provide (Brynjolfsson et al., 2013). Parente and Barki (2014) mention that clients can access the online information concerning the products even when they are inside a physical store and have contact with countless information including promotions, prices, advantages, and negotiations. According to Carvalho \& Campomar (2014), omnichannel "aims at integrating the available channels -physical and virtual ones- in order to conquer and to adapt to the consumer who demands fast answers and more options at the retail" (p. 103).

Based on the concepts and works mentioned above, we identified areas within ubiquitous learning that are currently deemed challenging so that further research and development in these fields could be explored. The previous reviews provided an important research synthesis on mobile learning and ubiquitous learning by analyzing various research articles. It has been observed that research has overlooked the review of context dimensions and the relationships between them. This is what motivated us to conduct this SMR. This review attempts to add value to the existing reviews by including an up-to-date synthesis of ubiquitous learning research articles mainly based on context-awareness. In contrast, we did not find works related to omnichannel for education. 


\section{Omnichannel for Education Proposal}

This section describes the components of an innovative product achieved through the aforementioned research methodology. Figure 2 shows the global vision of the proposal for applying omnichannel for education.

Figure 2: Omnichannel for Education proposal

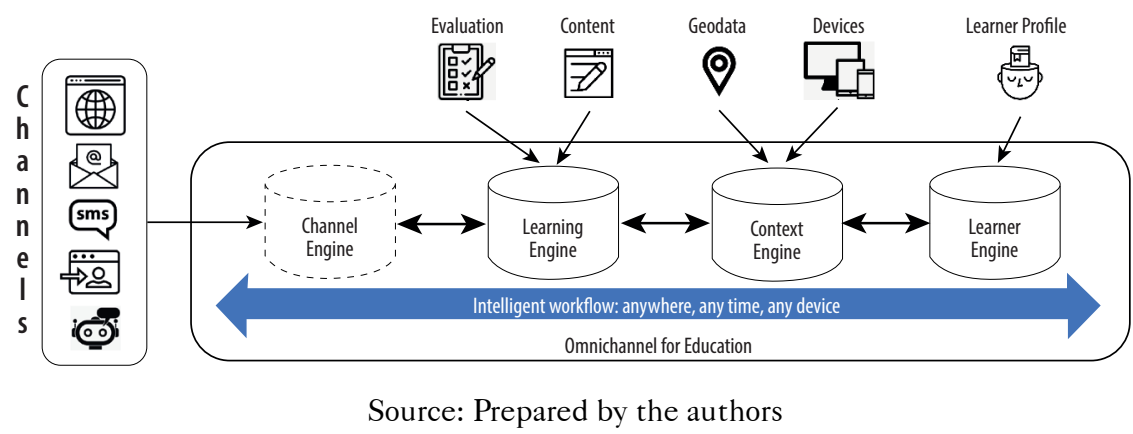

The proposal's components allowed us to manage information about learners, context-awareness, learning process, and channels through different engines to define and support the student's learning process.

- Learner Engine: Identifies the characteristics and particularities of the learners as personal information.

- Context Engine: Oversees the capturing of information from the learner's context in which the contents are used such as geolocation, device, Internet network quality, and ambient noise.

- Learning Engine: Provides study contents and evaluations to the learners.

- Channel Engine: Responsible for managing and articulating channels to achieve the omnichannel proposal according to each student's particularities based on the results of the Learner Engine. In this chapter, only web and email channels were tested.

These engines take an intelligent shape through a workflow that manages the main omnichannel characteristics. To develop and deploy the above-defined components, a research product called Omnilearning application was created. This web application provided a context- 
awareness environment where processes of mobile learning and ubiquitous learning could be analyzed. A set of context variables were captured in real-time where learners could document the learning workflow throughout a microlearning proposal consistent of videos and PDF files that motivated him/her to learn about a topic under his/her learning style. A set of interactions were prepared in the microlearning where learners provided data to an adaptive learning system, which suggested an improved action to the learner. The most appropriate assessment provided was in accordance to their profile, geolocation, and the most relevant available contents.

Figure 3 shows the main research components that guided the building of the application. It corresponds to a conceptual model designed to explain how channels and engines of Figure 2 work to guarantee an intelligent workflow that the student can follow anywhere, at any time, and using any device. A set of sub-models define the conceptual model. All of them have a set of entities that define the sub-models, functionality and dynamic interaction with each other.

Figure 3: Conceptual Model of a Learning Engine.

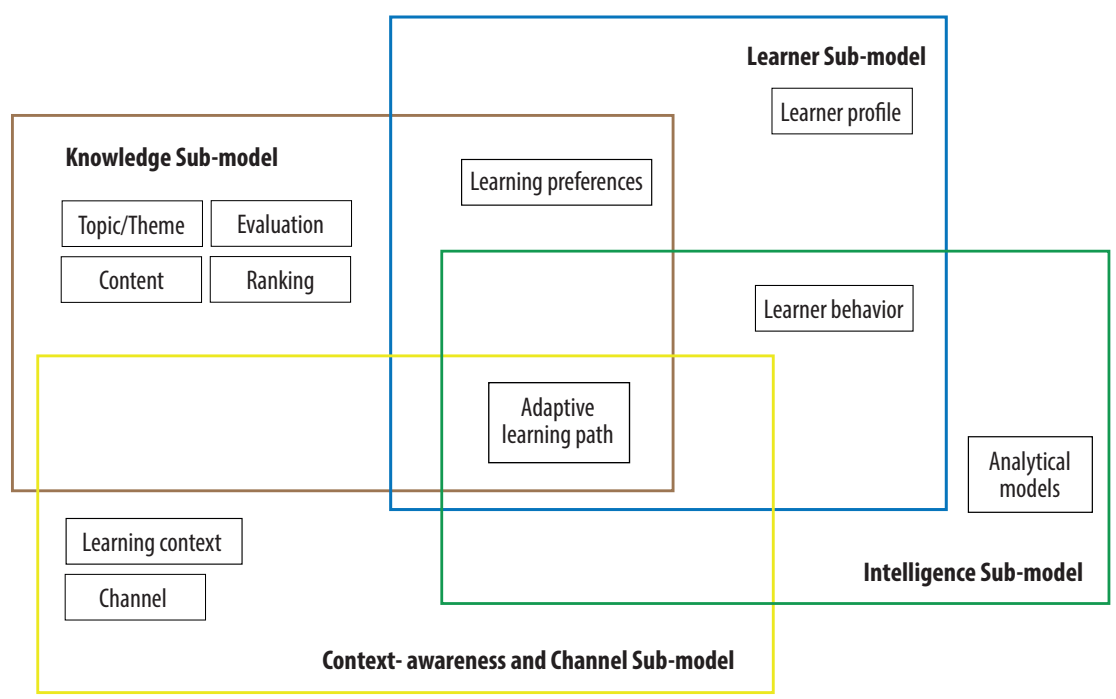

Source: Prepared by the authors 


\section{The Learner Sub-model}

The learner is the central element of the proposal. Entities and their characteristics in the sub-model allowed us to find particularities by using analytic models that could lead to personalized instructions. Figure 4 represents the user interfaces where learners registered personal information.

Figure 4: User Interfaces to capture personal learner information.
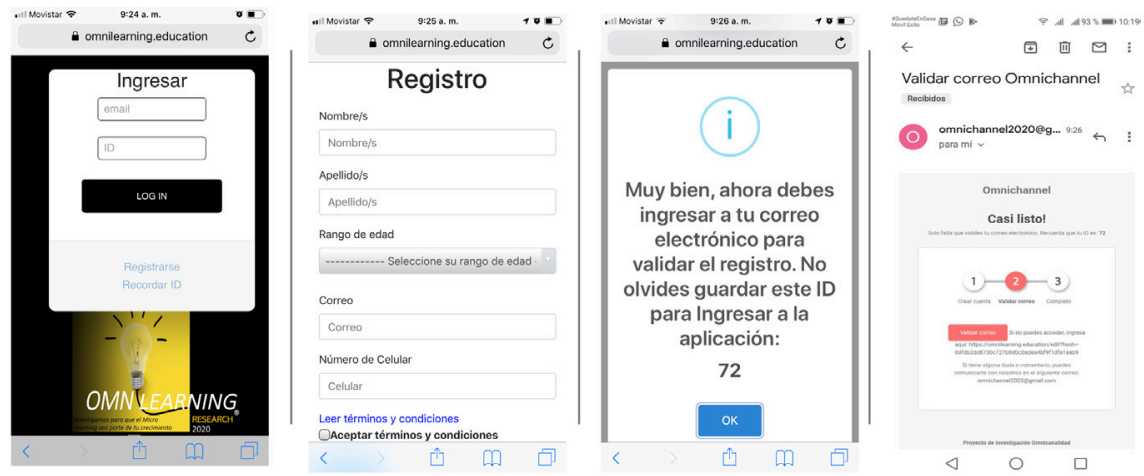

Source: Prepared by the authors

Once the learner is an Omnilearning application user, he/she can be profiled according to age. This is a way to understand why the learner chooses a learning path and allows the application to apply descriptive analytics models by finding adaptive alternatives to improve or personalize his/her learning style or opportunities. A pilot test of the Omnilearning application included a sample of 54 students of ICT and related areas. Those students were members of the Target Group and were between 15 and 65 years old. Figure 5 shows three plots that allow understanding the distribution of the learners by age groups. Figure 5(a) shows the age distribution of the people registered in the application during the pilot test. This allowed us to have an early learner's profile. Figure 5(b) shows how the learner age groups have accessed the contents. Figure 5(c) presents how the age groups' learners have advanced in the use of contents provided in the learning paths. For instance, a frequency value 
equal to 100 represents an age group that has accessed one or more contents entirely.

Figure 5: Descriptive analytics models by age groups.

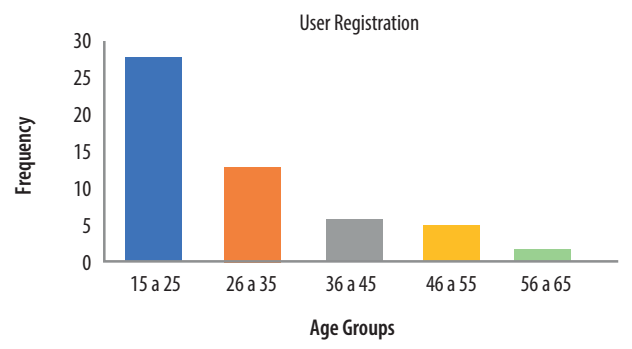

(a)Learners registration.

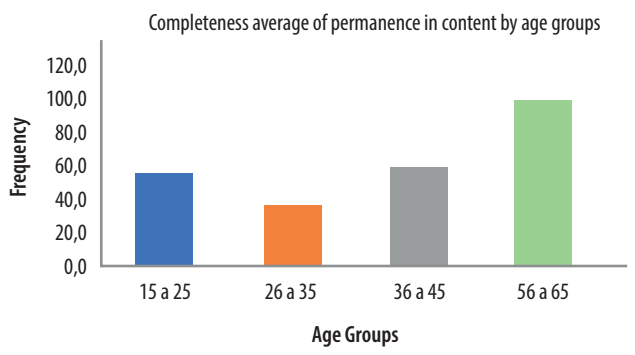

(b) Content access.

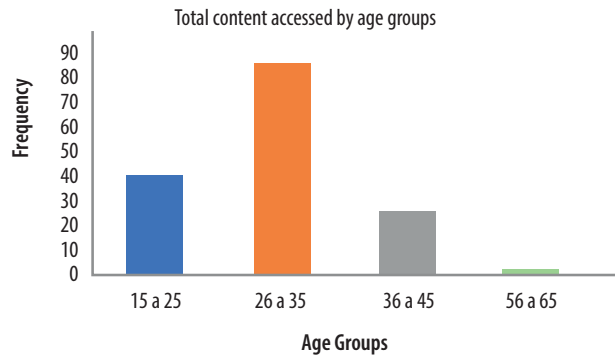

(c) Completeness of permanence in contents.

Source: Prepared by the authors 
Likewise, a learner can be profiled by his/her cognitive style, which is related to the structure the learner prefers when solving problems, making decisions, and processing information. These preferences varied across a broad spectrum ranging from highly adaptive to highly innovative. Bobic et al. (1999) proposed three dimensions of the Kirton Adaptation-Innovation Inventory where 32 items were grouped: Rule/ group conformity, Efficiency, and Originality.

It is simplified by choice-pairs of nine multiple selections to create an alternative measure (Altkirt). At one point in the pilot test, part of the Target Group (54 participants) had filled out the application responding to each of the nine proposal points. Figure 6 shows a comparative analysis showing the tendency for individuals to have an adaptive behavior. In other words, they are disposed to have a viewpoint characterized by reliability, efficiency, prudence, discipline, or they are more interested in solving problems rather than finding problems to solve. The innovator profile is determined by other cognitive characteristics that could identify him/her. It could drive the way on how learner knowledge points at preferences about a topic.

Figure 6: Cognitive style by age groups

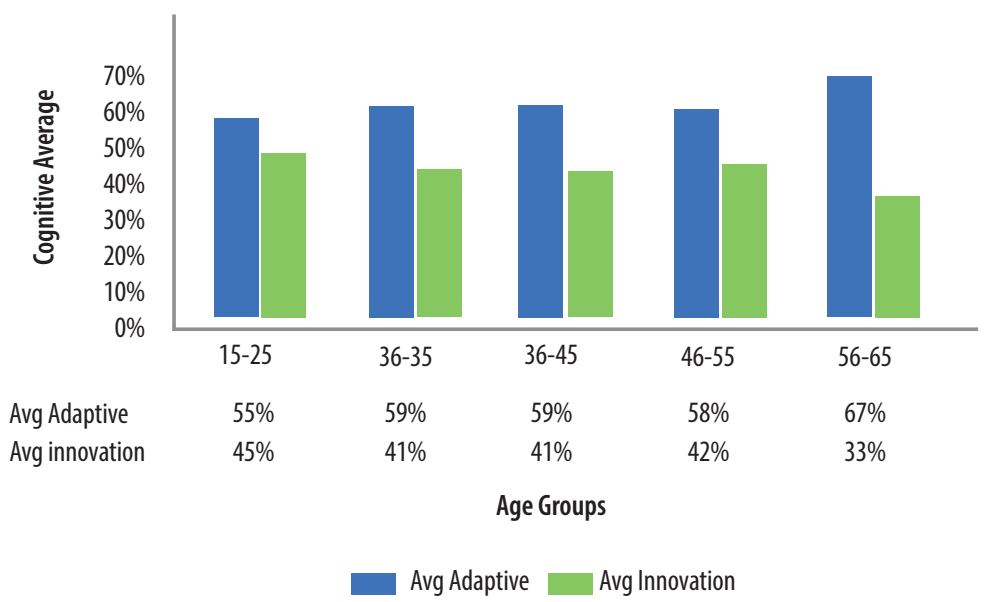

Source: Prepared by the authors 


\section{The Knowledge Sub-model}

This sub-model describes the knowledge resources that represent the structured domain knowledge (theme and topics associated with the theme) and the content that facilitates the appropriation of the concept by the learner.

Each topic has been structured considering pedagogical aspects such as learning objective, level of knowledge (basic, intermediate, advanced), logical sequence of the topic, and the set of questions that allow evaluating the learning of the topic. Each content is characterized by its category and type. The content category is associated with the preferred way of learning and has been defined in four categories: Motivation (introduction to the topic), Technical definition (definition of one concept), Example (implementation of a concept), and Code (implementation of a concept). On the other hand, the content type defines the different formats in which the content is presented. Another important entity of the knowledge model is the content ranking which helps measure the learner's perception of the contents.

The definition of the knowledge model is accompanied by its implementation in the Omnilearning application. A set of microlearning units define the topics and their contents. Following Göschlberger \& Bruck (2017), "microlearning refers to a didactic concept and approach that uses digital media to deliver small, coherent and self-contained content for short learning activities" (p. 545). Microlearning has become popular mainly due to the increase in the number of mobile devices and because it brings new possibilities for tracking learner activities and progress. The content is organized into short 2 to 10 -minute video lessons.

Figure 7 illustrates an example of the educational contents of the application. The content structure is based on the topic called "Software Design Patterns", which is distributed over four iterations: General aspects, Creational Patterns, Structural Patterns, and Behavioral Patterns. The learner can visualize his/her progress through color-coded graphic elements including the percentage of content not yet accessed (white), $50 \%$ or less of content accessed (yellow), and content fully accessed (green); the content visited progress bar; and an immediate display of the evaluation score. 
Figure 7: User interface of Contents and Evaluation.

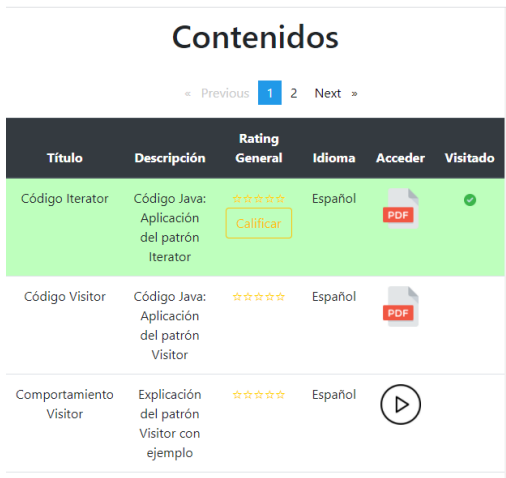

(a) Contents list view.

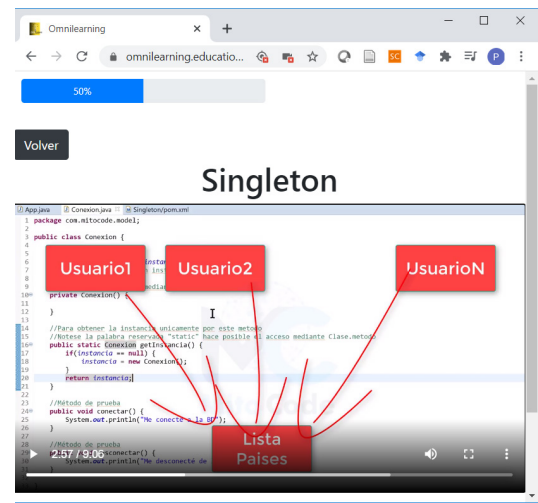

(c) Video content example.

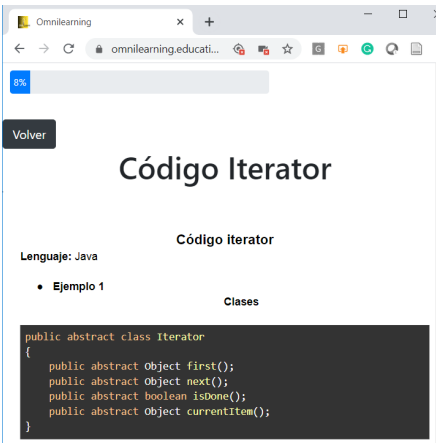

(b) PDF content example.

Evaluación

¿Qué son los patrones estructurales de diseño de software y cómo implementarlos? ¿Cuándo se utiliza el patrón Facede (fachada)?

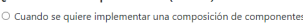

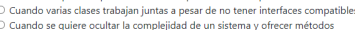
sencillos para el cliente ¿Para que sirven los patrones estructurales? Para definir la estructura de una aplicación

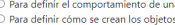
¿En cual de las siguientes situaciones se puede utilizar el patrón Proxy? O Se desea tener una unica entrada a los servicios de la capa de negocio
Se desea crear una estructura de herencia con relación reflexiva Se desea agregar ura tur
implementación bas Permite agregar una nuevo funcionalidad a un objeto sin modificar sut

0 Decorator
Composite ¿Cuál es el pal patrón usado para integrar el motor eléctrico al sistema de 0 Proxy

(d) Evaluation example.

Source: Prepared by the authors

When a user uses a content, he/she can vote depending on their satisfaction with the content. The vote is represented at 0 being the lowest score and 5 being the highest. Figure 8 presents the rating distribution of the contents. It also indicates the percentage of permanence in each content, where $100 \%$ represents that the content was viewed in its entirety. In general, the highest marks are given to content that was viewed for more than $50 \%$ of its total duration. 
Figure 8: Content Rating

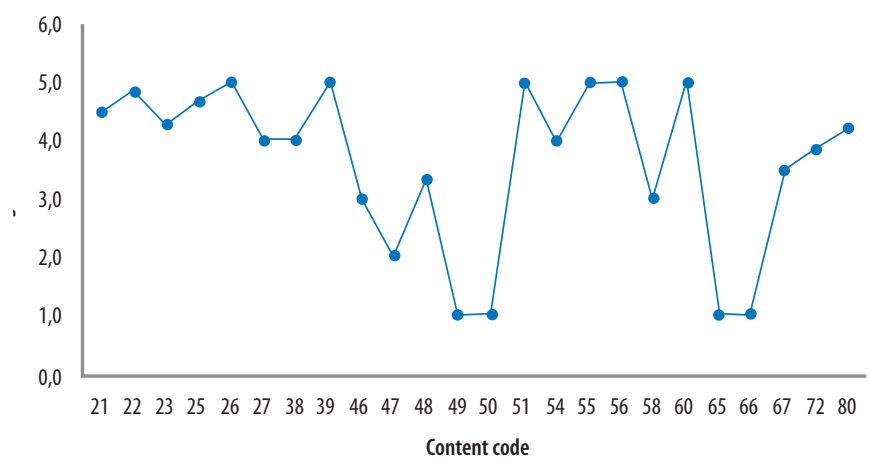

Source: Prepared by the authors

The evaluation allowed us to verify the understanding of the learner. In Omnilearning application, there is one evaluation for each iteration. An evaluation consists of five multiple-choice questions randomly selected and connects to information presented in the contents. There will always be at least one question related to a technical definition, at least one related to an example, and at least one related to a code presented in the contents. The learner has three opportunities to pass the evaluation. Each time he/she performs the evaluation, he/she receives the result, as well as the best obtained result.

\section{The Context-Awareness and Channel Sub-model}

This model represents the process of monitoring the environment's variables to identify special conditions that originate the automatic adaptation of the content type that will be presented in the personalized learning path. The omnichannel communication represents the technological mediators that facilitate the learning process by eliminating the barriers of time and space, and captures the context variables to achieve context-awareness anywhere, at any time, and with any device. In this work, we managed three types of channels: mobile, web browser, and email. Figure 9 illustrates the device usage by age groups. 
Figure 9: Device usage by age groups

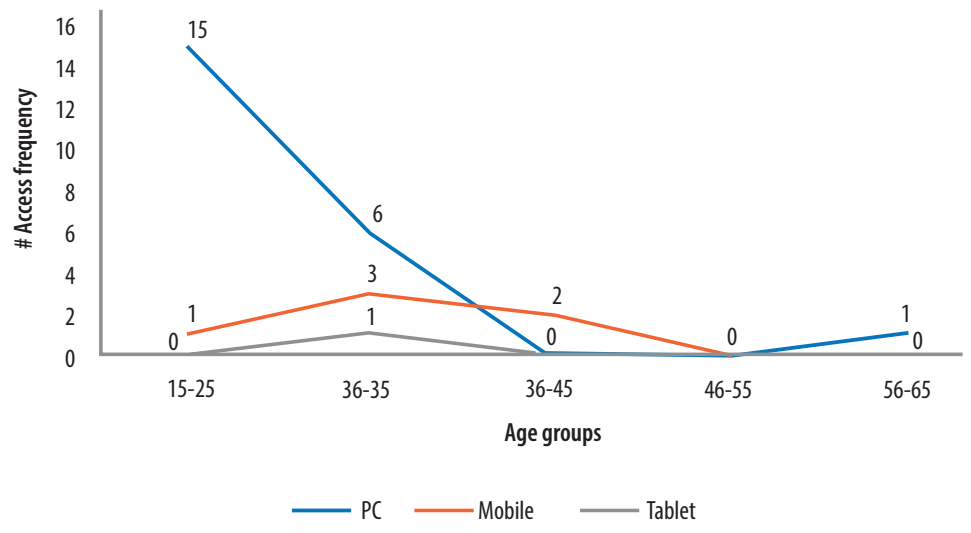

Source: Prepared by the authors

According to El Guabassi et al. (2018), the learning environment or learning context represents the attributes of a learning session (Mobility, Luminosity, Noise, Internet connectivity, and Location) which is monitored through context-awareness technology for a specific learning session. The learner's activities and achievements are monitored and analyzed to identify the characteristics of the context in which the student performs the learning activities. This monitoring also allows for analyzing the relationship between the characteristics of the context and the student's final achievement. The Omnilearning application captures the following context variables:

- Location (latitude and longitude): The places where the learner uses the application to access its contents or to carry out evaluations.

- Ambient noise: Captures the noise (in decibels) of the learner's study environment.

- Device type: Indicates whether the learner is connecting from a cell phone, a tablet, or a computer.

- Battery Level: Captures the battery level of the device used by the learner. 
- Network speed: Indicates the learner's Internet network speed. The possible values are $2 \mathrm{~g}$-slow, $2 \mathrm{~g}, 3 \mathrm{~g}$, and $4 \mathrm{~g}$.

- Accelerometer: Indicates if the learner makes any moves when accessing a content.

- Time in each content: Captures the time spent on the visited contents.

Other aspects that characterized the learner (adaptive learner path, learner profile, and learner behavior) were obtained through an analytical process based on data generated by the iteration and will be explained in the Intelligence sub-model. From the selected topic, the system generates the learning path that the learner must follow. The topic is associated with a learning iteration which is overcome when the learner answers the evaluation associated with the iteration (learning assessment).

\section{The Intelligence Sub-model}

This sub-model defines the analytic and machine learning models needed to characterize the learner's behavior, context-awareness during the learning process, the learner's learning style, the management of learning path contents, and its impact on the results measured by the evaluation proposed at the end of each microlearning course. Understanding, preparing, and evaluating the behavior of data and their support to the decision-making are the main functionalities of this model. At the same time, the collected data and other required models could adapt the knowledge resource to different contexts to provide learners with the best match for their current situation. For instance, Figure 10 shows five clusters that represent learning periods where a set of users accessed different contents. These timeslots are defined in the following categories:

- Early bird: 00h - 06h

- Morning: 06h - 12h

- Afternoon: 12h - 17h

- Evening: $17 \mathrm{~h}-21 \mathrm{~h}$

- Night: $21 \mathrm{~h}-00 \mathrm{~h}$ 
Figure 10: Clusters of Learning periods preferred by learners

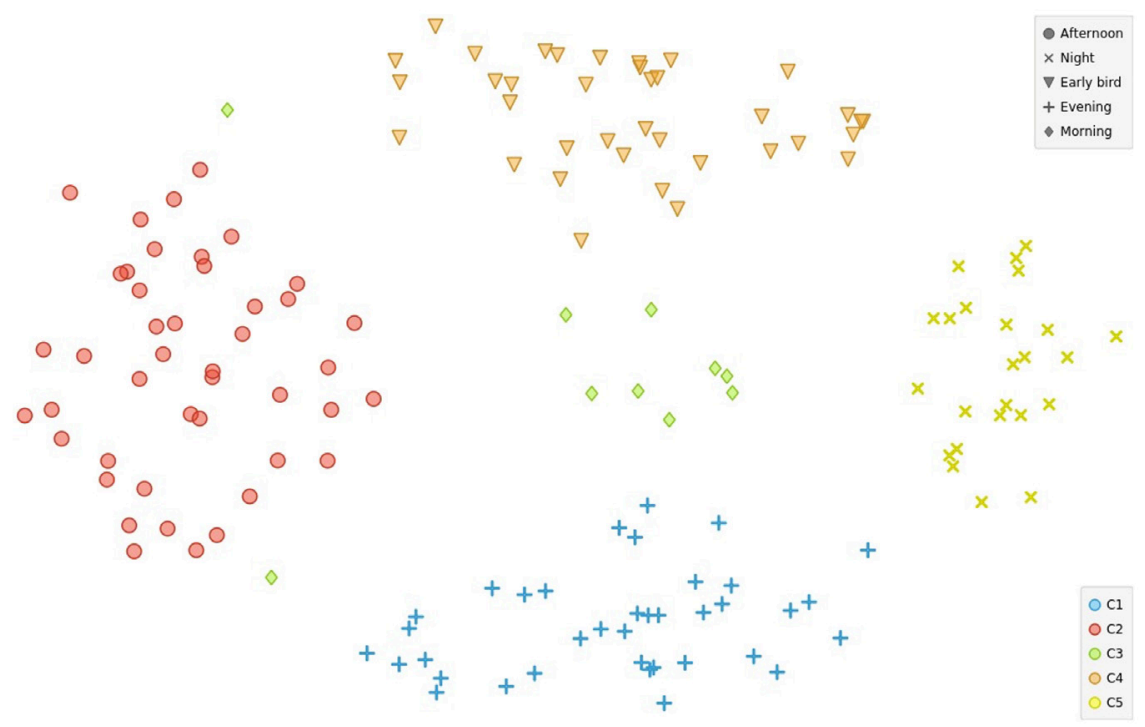

Source: Prepared by the authors

Figure 11 shows two dispersion plots that allow us to understand how learners perceived the contents.

Figure 11: Permanence in preferred contents

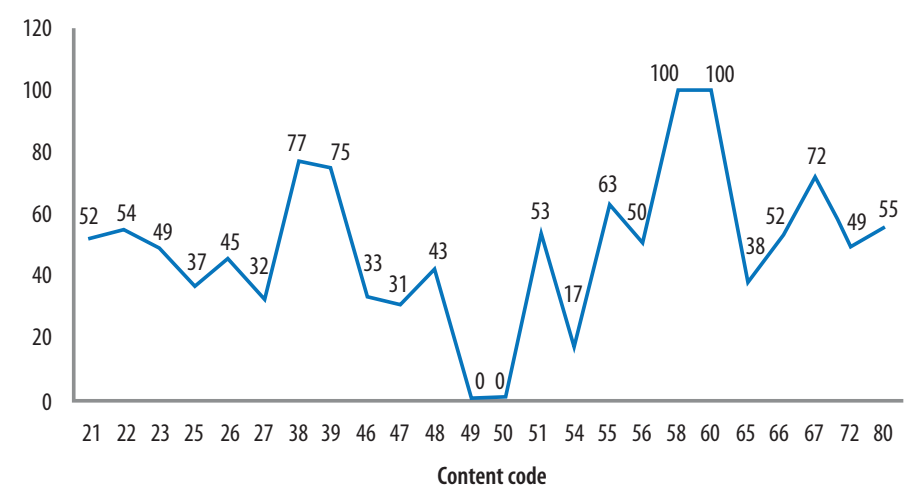

Source: Prepared by the authors 


\section{Results and Conclusion}

The integration of diverse methodologies for the development of our proposal generated a dynamic teamwork by improving communication, team collaboration, and maintaining constant interaction with the Target Group. Design Thinking and Scrum followed a user-centric approach which allowed the Project Team to have a direct relationship with the Target Group, making it easier for the resulting product to satisfy their needs completely. Simultaneously, Lean Startup and ASUM-DM allowed for scientific experimentation to guarantee a quality product completed in a short period.

The Project Team confirmed that this proposal is two-fold, meaning:

- A proposal based on three pillars: the student profile, the knowledge resources (contents) and context-awareness management, and the omnichannel communication mechanisms. These pillars were centered on the learner and their learning profile to optimize his/her learning. The conceptual model allowed the learner to follow a flow of access to content anywhere, any time, and from any device.

- The implementation of the proposal in the Omnilearning application and the initial experimental results were obtained from a case study with ICT students.

Bearing in mind that our target audience was primarily digital natives, our proposal integrated features for users to feel more motivated to use it. For example, the Omnilearning application provided immediate feedback regarding student progress through graphic elements such as the percentage of content represented with white, yellow, and green colors; a content visited progress bar; and the immediate display of the evaluation score. It also provided microlearning spaces to encourage student concentration and generated challenges and ways to establish new learning styles. The elements were accessible through mobile devices.

Regarding the question: Why not use omnichannel marketing strategies to educate better and with more coverage and greater efficiency and impact?, our proposal applied some of the characteristics of omnichannel in an educational context. The Omnilearning application distributed information to the learners through different channels: 
mobile (access to the Omnilearning application and all its features), web browser (access to the Omnilearning application with limited access to contextual awareness functions), and email (communication of important milestones such as completing an iteration or the outcome of an evaluation). In conclusion, it is possible to improve the efficiency and impact on education using distribution and communication strategies like those used in marketing. These characteristics provide experiential learning and identify the restrictions and conditions related to its use at any given time.

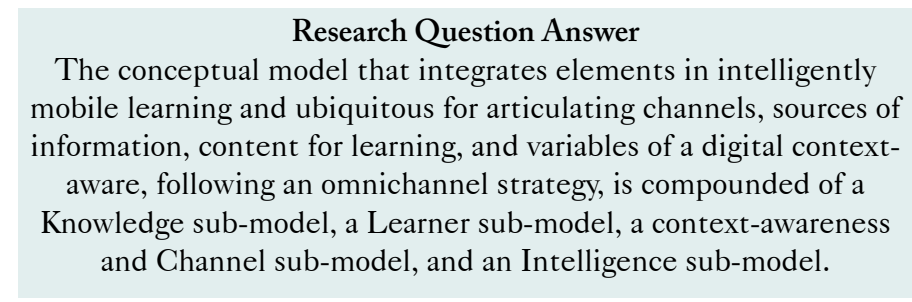

The proposal integrated the main characteristics of omnichannel to guarantee that the learner was the central element. The main objective was to offer him/her an appropriate learning experience according to the context's characteristics. The application followed consistency and defined the parameters that helped the user complete tasks practically preventing the user to have to undertake a new learning process when accessing from a different device. The proposal considered the context essential and helped define an appropriate road map to make the right decisions for the learner. The application followed a pedagogical strategy that guided students in their learning process through the proposed contents and evaluations.

The research results proved the significant contribution of omnichannel strategies in education. Simultaneously, it proved a direct relationship between learners and mobile devices used during the learning process. The context variables and final students' outcomes provide new knowledge to the decision-making. This research also highlights the way how many technologies and tools can be successfully involved in the learning process and provides a straightforward application of modern educational ubiquitous and mobile approaches. 
Further research and development will focus on:

- Products of new knowledge and dissemination: articles published in high impact journals, and articles in events.

- Knowledge dissemination products: seminar on technology.

- Knowledge network.

- Technological development and innovation products.

- Integrate more channels such as chat, chatbot, two-way SMS, landing pages, voice, among others to facilitate the capture of information through the interaction of individuals with available digital content, and a ubiquitous context-aware.

\section{References}

Al-Emran, M., Mezhuyev, V., \& Kamaludin, A. (2018). Technology Acceptance Model in m-learning Context: A systematic review. Computers \& Education, $125,389-412$.

Alsswey, A., \& Al-Samarraie, H. (2019). M-Learning Adoption in the Arab Gulf Countries: A Systematic Review of Factors and Challenges. Education and Information Technologies, 24, 3163-3176.

Angée, S., Lozano-Argel, S. I., Montoya-Munera, E. N., Ospina-Arango, JD., Tabares-Betancur, M. S. (2018). Towards an Improved ASUM-DM Process Methodology for Cross-Disciplinary Multi-organization Big Data \& Analytics Projects. In L. Uden., B. Hadzima, I. Ting (Eds.), Knowledge Management in Organizations. KMO 2018. Communications in Computer and Information Science (vol 877, pp. 613-624). Springer. https://doi.org/10.1007/978-3-319-95204-8_51

Antioquia, G. (2016). Plan de Desarrollo Antioquia Piensa en Grande 20162019. http://antioquia.gov.co/images/pdf/bases\%del\%plan\%de\%desarrollo.

Bobic, M., Davis, E., \& Cunningham, R. (1999). The Kirton AdaptationInnovation Inventory: Validity Issues, Practical Questions. Review of Public Personnel Administration, 19(2), 18-31.

Brynjolfsson, E., Hu, Y. J., \& Rahman, M. S. (2013). Competing in the Age of Omnichannel Retailing. MIT Sloan Management Review, 54(4), 23-29.

Byun, H. E., \& Cheverst, K. (2004). Utilizing Context History to Provide 
Dynamic Adaptations. Applied Artificial Intelligence, 18(6), 533-548.

Cárdenas-Robledo, L.A., \& Peña-Ayala, A. (2018). Ubiquitous Learning: A Systematic Review. Telematics and Informatics, 35(5), 1097-1132.

Carvalho, J. L. G., \& Campomar, M. C. (2014). Multichannel at Retail and Omni-channel: Challenges for Marketing and Logistics. Business and Management Review, 4(3), 103-113.

Croll, A., \& Yoskovitz, B. (2013). Lean Analytics: Use data to Build a Better Startup Faster. O'reilly.

DANE. (2019). Población de Colombia es de 48,2 millones de habitantes, según el DANE. https://id.presidencia.gov.co/Paginas/prensa/2019/190704-Poblacionde-Colombia-es-de-48-2-millones-habitantes-segun-DANE.aspx

El Guabassi, I., Bousalem, Z., Al Achhab, M., Jellouli, I., \& Mohajir, B. E. E. (2018). Personalized Adaptive Content System for Context-aware Ubiquitous Learning. Procedia Computer Science, 127, 444-453.

Gobernación de de Antioquia. (2016). Plan de desarrollo Antioquia piensa en grande 2016-2019. http://antioquia.gov.co/images/pdf/BASES\%DEL\% PLAN\%DE\%DESARROLLO.

González Videgaray, Maricarmen. (2007). Assessment of Student and Teacher's Reaction in a Blended Learning Model for Higher Education. Relieve-Revista Electrónica de Investigación y Evaluación Educativa, 13, 83-103.

Göschlberger, B., \& Bruck, B. A. (2017, December). Gamification in Mobile and Workplace Integrated Microlearning. [Conference Paper]. In Proceedings of the 19th International Conference on Information Integration and Web-based Applications \& Services (iiWAS2017), Salzburg (pp. 545-552). ACM Press. https://doi.org/10.1145/3151759.3151795

Guri-Rosenblit, S. (2005). 'Distance Education' and 'e-learning': Not the Same Thing, Higher Education, 49, 467-493.

https://doi.org/10.1007/s10734-004- 0040-0

Hasanov, A., Laine, T., \& Chung, T. S. (2019). A survey of Adaptive Context- aware Learning Environments. Journal of Ambient Intelligence and Smat Environments, 11(5), 403-428. https://doi.org/10.3233/AIS-190534

Hevner, R., March, S. T., Park, J., \& Ram, S. (2004). Design Science in Information Systems Research. MIS Quarterly, 28(1), 75-105. 
Hicks, B., Larsson, A., Culley, S. \& Larsson, T. (2009). A methodology for Evaluating Technology Readiness during Product Development [Conference Paper]. In Proceedings of ICED 09, the 17th International Conference on Engineering Design, Palo Alto (pp. 299-310). ICED.

Hwang, G. J., Tsai, C. C., \& Yang, S. J. (2008). Criteria, Strategies and Research Issues of Context-aware Ubiquitous learning. Journal of Educational Technology \& Society, 11(2), 81-91.

Informe Nacional de Competitividad. (2017). Informe Nacional de Competitividad 2017-2018, https://compite.com.co/informe/informe-nacionalde-competitividad-2017-2018/.

Juaneda-Ayensa, E., Mosquera, A., \& Sierra Murillo, Y. (2016). Omnichannel Customer Behavior: Key Drivers of Technology Acceptance and Use and their Effects on Purchase Intention. Frontiers in Psychology, 7, 1-11.

Khanal, S. S., Prasad, P., Alsadoon, A., \& Maag, A. (2019). A systematic review: Machine Learning Based Recommendation Systems for e-learning. Education and Information Technologies 25(6), 1-30.

Kotler, P., \& Keller, K. (2012). Administração de Marketing. São Paulo. Pearson. Kukulska-Hulme, A. (2005). Mobile Usability and User Experience. In $A$. Kukulska-Hulme \&̊ J. Traxler (Eds.), Mobile Learning: A handbook for educators and trainers (pp. 45-65). Routledge.

Kumar, B. A., \& Sharma, A. (2019). Context Aware Mobile Learning Application Development: A Systematic Literature Review. Education and Information Technologies, 25, 2221-2239.

Lewrick, M., \& Link, P. (2018). The Design Thinking Playbook: Mindful Digital Transformation of Teams, Products, Services, Businesses and Ecosystems. John Wiley \& Sons.

Lucke, U., \& Rensing, C. (2014). A Survey on Pervasive Education. Pervasive and Mobile Computing, 14, 3-16. doi.org/10.1016/j.pmcj.2013.12.001

Martin, S., Diaz, G., Plaza, I., Ruiz, E., Castro, M., \& Peire, J. (2011). State of the Art of Frameworks and Middleware for Facilitating Mobile and Ubiquitous Learning Development. Journal of Systems and Software, 84(11), 1883-1891.

Muñoz, J., \& González, C. (2019). Assessment in Mobile Learning System: A Literature Review. Revista Iberica de Sistemas e Tecnologias de Informacao, 187-199. 
Nye, B. D. (2015). Intelligent Tutoring Systems by and for the Developing World: A Review of Trends and Approaches for Educational Technology in a Global Context International Journal of Artificial Intelligence in Education, 25, 177-203.

O'Cathain, A., Thomas, K., \& Drabble, S. (2014). A Systematic Mapping Review of Published Qualitative Research Undertaken with Specific Randomised Controlled Trials. In A. O'Cathain, K. J. Thomas, S. J. Drabble, A. Rudolph, J. Goode, \& J. Hewison (Eds.) Maximising the value of combining qualitative research and randomised controlled trials in health research: the QUAlitative Research in Trials (QUART) study - a mixed methods study (pp. 7-81). NIHR Journals Library. https://doi.org/10.3310/hta18380

Parente, J., \& Barki, E. (2014). Varejo no Brasil: gestão e estratégia. Atlas.

Pinkwart, N., Hoppe, H. U., Milrad, M., \& Perez, J. (2003). Educational Scenarios for Cooperative Use of Personal Digital Assistants. Journal of Computer Assisted Learning, 19, 383-391.

Prensky, M. (2001). Digital Natives, Digital Immigrants Part 1. On the Horizon, 9(5), 1-6. https://doi.org/10.1108/10748120110424816

Schwaber, K. (2004). Agile Project Management with Scrum. Microsoft Press.

Quinn, C. (2000). mLearning: Mobile, Wireless, In-Your-Pocket Learning. Line Zine, 1-2.

Siadaty, M., Torniai, C., Gašević, D., Jovanovic, J., Eap, T., \& Hatal, M. (2008, June). m- loco: An ontology-based Framework for Context-aware Mobile Learning [Conference Paper]. In Workshop on Ontologies and Semantic Web for Intelligent Educational Systems at the 9th Int. Conf. on Intelligent Tutoring Systems, Montreal, (pp. 21-35).

Ries, E. (2011). The Lean Startup: How Today's Entrepreneurs Use Continuous Innovation to Create Radically Successful Businesses. Crown Business.

Salber, D., Dey, A. K., \& Abowd, D. G. (1999, May). The Context Toolkit: Aiding the Development of Context-enabled Applications [Conference Paper]. In Proceedings of the SIGCHI Conference on Human Factors in Computing Systems, Pittsburgh, (pp. 434-441). ACM Press. https://doi.org/10.1145/302979.303126

UNIR Research. (2016). UNESCO-UNIR ICT \& Education Latam Congress 2016. http://research.unir.net/unesco-congreso/ 
Verbert, K., Manouselis, N., Ochoa, X., Wolpers, M., Drachsler, H., Bosnic, I., \& Duval, E. (2012). Context-aware Recommender Systems for Learning: A Survey and Future Challenges. IEEE Transactions on Learning Technologies, 5(4), 318-335.

Wang, H. Y., Liu, G.-Z., \& Hwang G. J. (2017). Integrating Socio-cultural Contexts and Location-based Systems for Ubiquitous Language Learning in Museums: A State of the Art Review of 2009-2014. British Journal of Educational Technology, 48(2), 653-671.

Wu, W.-H., Jim Wu, Y.-C., Chen, C.-Y., Kao, H.-Y., Lin, C.-H., \& Huang, S.-H. (2012). Review of Trends from Mobile Learning Studies: A Meta-analysis. Computers $\mathbb{E}$ Education, 59(2), 817-827.

https://doi.org/10.1016/j.compedu.2012.03.016.

Zhao, X., Wan, X., \& Okamoto, T. (2010, April). Adaptive Content Delivery in Ubiquitous Learning Environment [Conference Paper]. In Proceedings of the 6th IEEE International Conference on Wireless, Mobile, and Ubiquitous Technologies in Education, Kaohsiung (pp. 19-26). IEEE.

https://doi.org/10.1109/WMUTE.2010.10

Zmuda, A., Curtis, G., \& Ullman, D. (2015). Learning personalized: the evolution of the contemporary classroom. Wiley Blackwell. 